\title{
IL-22/IL-22R1 promotes proliferation and collagen synthesis of MRC-5 cells via the JAK/STAT3 signaling pathway and regulates airway subepithelial fibrosis
}

\author{
JUAN LIU, BIAO SHANG and JING BAI \\ Department of Pediatrics, Nanchong Central Hospital, The Second Clinical Medical College, \\ North Sichuan Medical College, Nanchong, Sichuan 637000, P.R. China
}

Received April 16, 2019; Accepted March 17, 2020

DOI: $10.3892 /$ etm.2020.8931

\begin{abstract}
Asthma in children poses a threat to their health, but the mechanism remains to be elucidated. The present study investigated the mechanism by which the interleukin (IL)-22/IL-22 receptor 1 (IL-22R1) signaling pathway regulates subepithelial fibrosis in children with asthma. A total of 41 children with asthma and 12 healthy children were included in the present study. ELISA was performed to measure the content of IL-22 in peripheral blood. Serum from children with asthma was used to incubate MRC-5 cells and IL-22 antibody rescued the effect of IL-22 on the biological functions of MRC-5 cells. Reverse transcription-quantitative PCR was performed to determine IL-22R1 mRNA expression levels and western blotting was performed to measure IL-22R1 protein expression. The Cell Counting Kit-8 assay was used to analyze cell proliferation and flow cytometry was performed to assess the cell cycle distribution of MRC-5 cells. The expression of IL-22 was elevated in peripheral blood from children with asthma, which promoted the proliferation of MRC-5 cells, possibly via the upregulation of collagen type I $\alpha 1$ chain (COL1 $\alpha 1)$ and collagen type I $\alpha 2$ chain (COL1 $\alpha 2)$. IL-22 exerted its biological functions via IL-22R1. The IL-22/IL-22R1 signaling pathway regulated the proliferation of MRC-5 cells and the expression of COL1 11 and COL1 $\alpha 2$ in MRC-5 cells via the JAK/STAT3 signaling pathway. Mononuclear lymphocytes from children with asthma stimulated the proliferation and secretory function of fibroblasts by secreting IL-22. The present study suggested that IL-22 expression in peripheral blood of children with asthma is upregulated compared with the control group. Furthermore, the present study indicated
\end{abstract}

Correspondence to: Dr Juan Liu, Department of Pediatrics, Nanchong Central Hospital, The Second Clinical Medical College, North Sichuan Medical College, 97 South Renmin Road, Nanchong, Sichuan 637000, P.R. China

E-mail:nk9002@163.com

Key words: interleukin-22, interleukin-22 receptor 1, JAK-STAT3 signaling pathway, airway subepithelial fibrosis that the IL-22/IL-22R1 signaling pathway promoted MRC-5 cell proliferation and collagen synthesis by activating the JAK/STAT3 signaling pathway, thereby potentially regulating airway subepithelial fibrosis.

\section{Introduction}

Bronchial asthma results from chronic allergic inflammation of the airway, characterized by airway hyperresponsiveness, airflow limitation and decreased lung function (1). Airway inflammation and remodeling are the main pathological features of bronchial asthma (2). With the rapid development of the economy, environmental pollution has become increasingly serious and the incidence of bronchial asthma in children has been increasing each year (3). Airway remodeling occurs not only in severe or late-stage asthma, but also during the early stages of mild asthma and childhood asthma (4). Therefore, it has been suggested that airway remodeling may be a cause of refractory asthma (5). The mechanism of airway remodeling during the early stages of bronchial asthma is an important prognostic factor for children with bronchial asthma (6).

Airway remodeling primarily refers to changes in the size or number of tissue components during airway development or occurs as a result of injury and/or inflammation $(7,8)$. Pathological changes in airway remodeling include epithelial cell exfoliation, inflammatory cell infiltration, extracellular matrix deposition, reticular basement membrane thickening, submucosal goblet cell proliferation, fibroblast proliferation, smooth muscle proliferation and hypertrophy, angiogenesis and airway wall thickening (9-11). Previous studies have reported that a large number of lung fibroblasts exist in lung tissue and these cells maintain the integrity of the lung tissue structure and function by synthesizing extracellular matrix and cytokines $(12,13)$. When lung tissues are damaged, fibroblasts become dysfunctional and can be transformed into extracellular matrix or lung fibroblasts with strong cytokine synthesis ability, ultimately leading to pulmonary inflammation and fibrotic processes $(14,15)$.

Interleukin (IL)-22 is a cytokine that belongs to the IL-10 family $(16,17)$. IL-22 is primarily synthesized and secreted by macrophages, dendritic cells, natural killer T (NKT) cells and natural killer (NK) cells, and can bind to the IL-22 receptor 1 (IL-22R1) and IL-10 receptor 2 (IL-10R2) to activate the 
mitogen-activated protein kinase (MAPK) or JAK/STAT signaling pathways (18). IL-22 plays an important role in multiple sclerosis, arthritis and wound tissue repair (19-21). However, it is unclear whether the IL-22/IL-22R1 signaling pathway plays a role in the regulation of airway subepithelial fibrosis caused by fibroblasts. Inflammatory factors such as tumor necrosis factor (TNF)- $\alpha$ and IL-37 play a role in airway remodeling as they can activate various signaling pathways, such as STAT3 and $\mathrm{NF}-\kappa \mathrm{B}$ and regulate the biological functions of cells. IL-22 has been reported to activate the JAK/STAT3 signaling pathway. Furthermore, STAT3 participates in airway remodeling (22). Therefore, the present study investigated the relationship between airway remodeling and the IL-22/IL-22R1 signaling pathway in bronchial asthma.

\section{Materials and methods}

Subjects. A total of 41 children with bronchial asthma who had received treatment at the Department of Pediatrics, Nanchong Central Hospital between May 2015 and December 2017 were included in the experimental group (27 male patients and 14 female patients; mean age, 10.6 \pm 2.6 years). All subjects in the experimental group met the diagnostic criteria detailed in the Guidelines for the Prevention and Treatment of Bronchial Asthma formulated by the Asthma Group of the Society of Respiratory Diseases of the Chinese Medical Association (23). Additionally, 12 healthy children who had undergone physical examinations at the Physical Examination Center of Nanchong Central Hospital between May 2015 and December 2017 were included in the control group (8 male patients and 4 female patients; mean age, $12.2 \pm 1.8$ years). The inclusion criteria for all the subjects were: i) No recent history of acute infection; ii) no immune diseases, for example ulcerative colitis, kidney disease and rheumatoid arthritis; and iii) no administration of hormone drugs orally or intravenously in the past month. Peripheral blood $(10 \mathrm{ml})$ was collected from median cubital veins of all the participants and was stored evenly between two blood tubes ( $5 \mathrm{ml}$ each). One tube was used for the separation of serum by centrifugation at $600 \mathrm{x}$ g and $4^{\circ} \mathrm{C}$ for $5 \mathrm{~min}$, and the other tube was used for the separation of mononuclear lymphocytes. To obtain peripheral blood mononuclear cells (PBMCs), the mixture of heparin-anticoagulant venous blood and equal amount of serum-free Iscove's modified Dulbecco's medium (v/v, 1:1; Stemcell Technologies, Inc.) was gently added onto lymphocyte separation medium before centrifugation at $25^{\circ} \mathrm{C}$ and $400 \mathrm{x}$ g for $30 \mathrm{~min}$. Following centrifugation, the middle layer was aspirated and mixed with $20 \mathrm{ml} \mathrm{Hank's} \mathrm{Balanced}$ Salt Solution before centrifugation at $25^{\circ} \mathrm{C}$ and $300 \mathrm{x} \mathrm{g}$ for $10 \mathrm{~min}$. After washing the cells twice, the cells were counted and diluted to a density of $1 \times 10^{6} / \mathrm{ml}$. Finally, $3 \times 10^{6}$ cells were seeded onto a round culture plate with a bottom area of $9 \mathrm{~cm}^{2}$, followed by incubation at $37^{\circ} \mathrm{C}$ and $5 \% \mathrm{CO}_{2}$ for $1-2 \mathrm{~h}$. The cells that attached on the bottom were PBMCs.

All the procedures were approved by the Ethics Committee of North Sichuan Medical College (approval no. NS-CE-017-03). Written informed consent was obtained from the guardians of all participants.

Cells. The human embryonic lung fibroblast cell line MRC-5 was purchased from the Cell Bank of Type Culture Collection,
Chinese Academy of Sciences. Prior to transfection, MRC-5 cells $\left(2 \times 10^{5}\right)$ in the logarithmic growth phase were seeded into 24-well plates and cultured in antibiotic-free RPMI-1640 medium (Thermo Fisher Scientific, Inc.) supplemented with 10\% fetal bovine serum (FBS; Thermo Fisher Scientific, Inc.) at room temperature until $70 \%$ confluency was reached. In the first vial, $1.5 \mu \mathrm{l}$ small-interfering (si)RNA of IL-22R1 (siR-IL-22R1; $50 \mathrm{pmol} / \mu \mathrm{l} ;$ 5'-GGTCTACAGCATCGAGTA T-3'; Hanbio Biotechnology Co., Ltd.) or negative control (si-NC; cat. no. siN0000001-1-10; Guangzhou RiboBio Co., Ltd.) was mixed with $50 \mu \mathrm{l}$ Opti Mem medium (Thermo Fisher Scientific, Inc.). In the second vial, $1 \mu 1$ Lipofectamine $^{\circledR}$ 3000 (Thermo Fisher Scientific, Inc.) was mixed with $50 \mu 1$ Opti Mem medium. After $5 \mathrm{~min}$, the two vials were combined for $20 \mathrm{~min}$ at room temperature. Subsequently, the mixtures $(500 \mu \mathrm{l})$ were added onto cells in siR-NC and siR-IL-22R1 groups, respectively. After incubation at $37^{\circ} \mathrm{C}$ for $6 \mathrm{~h}$, the medium was replaced with RPMI-1640 medium containing $10 \%$ FBS. After a 48 -h incubation at $37^{\circ} \mathrm{C}$, the cells were collected for further analysis. To evaluate the effect of patient serum on fibroblasts, serum from children with asthma or healthy children was mixed with complete medium (Thermo Fisher Scientific, Inc.) at a ratio of 1:1 to make conditioned medium for the culture of MRC-5 cells for $24 \mathrm{~h}$. MRC-5 cells that were not incubated with serum was used as a control group. For rescue experiments, $1 \mu \mathrm{g}$ IL-22 antibody (1:1,000; cat. no. ab18498; Abcam) was added into the asthma serum group of MRC-5 cells, which were incubated at $37^{\circ} \mathrm{C}$ and $5 \% \mathrm{CO}_{2}$ for $12 \mathrm{~h}$ as the rescue group.

Transfection of cells with pcDNA-3.1-IL-22R1 mimics (0.5 $\mu \mathrm{g} /$ well; Hanbio Biotechnology Co., Ltd.) or empty pcDNA-3.1 vector $(0.5 \mu \mathrm{g} /$ well; NC; Hanbio Biotechnology Co., Ltd.) was performed according to the same protocol as siRNA transfection. To inhibit the JAK/STAT3 signaling pathway, the JAK/STAT3 signaling pathway inhibitor stattic (2 $\mu \mathrm{M}$; MedChemExpress) was added to MRC-5 cells and incubated at $37^{\circ} \mathrm{C}$ and $5 \% \mathrm{CO}_{2}$ for $2 \mathrm{~h}$ following stimulation by IL-22.

Mononuclear lymphocytes (1×10\%/well) were added onto wells containing MRC-5 cells, and incubated in DMEM (Thermo Fisher Scientific, Inc.) supplemented with $10 \%$ fetal bovine serum (Thermo Fisher Scientific, Inc.) at $37^{\circ} \mathrm{C}$ and $5 \% \mathrm{CO}_{2}$ for $12 \mathrm{~h}$.

ELISA. The IL-22 ELISA kit (cat. no. ab216170; Abcam) was used to determine the concentration of IL-22 in patient-derived serum according to the manufacturer's protocol. In microplates, IL-22 standards (100 $\mu \mathrm{l})$ and serum samples $(100 \mu \mathrm{l})$ were added into pre-defined wells, while blank wells were left empty. In the wells containing standards or samples, horseradish peroxidase-labeled conjugates $(100 \mu \mathrm{l})$ were added before sealing the plates for incubation at $37^{\circ} \mathrm{C}$ for $1 \mathrm{~h}$. After washing the plates with PBS five times, substrates A $(50 \mu \mathrm{l})$ and $\mathrm{B}(50 \mu \mathrm{l})$ were added into each well. After incubation at $37^{\circ} \mathrm{C}$ for $15 \mathrm{~min}$, stop solution $(50 \mu \mathrm{l})$ was added into each well, and the absorbance of each well was measured at a wavelength of $450 \mathrm{~nm}$. Each experiment was repeated three times.

Reverse transcription-quantitative PCR (RT-qPCR). MRC-5 cells were cultured in six-well plates $\left(1 \times 10^{6}\right.$ cells/well $)$ and 
lysed using $1 \mathrm{ml}$ TRIzol reagent (Thermo Fisher Scientific, Inc.) according to the manufacturer's protocol. Total RNA was extracted using the phenol chloroform method. SDS-PAGE (10\%) was used to detect the integrity of RNA bands $(28,18$ and $5 \mathrm{~S}$ ). The concentration and quality of RNA were measured by ultraviolet spectrophotometry using a Nanodrop ND2000 spectrophotometer (Thermo Fisher Scientific, Inc.). cDNA was obtained by reverse transcription of $1 \mu \mathrm{g}$ RNA using the TIANScript II cDNA First Strand Synthesis kit (Tiangen BioTech Co., Ltd.) according to the manufacturer's protocol and was subsequently stored at $-20^{\circ} \mathrm{C}$ until further analysis.

The SuperReal PreMix (SYBR Green) qPCR kit (Tiangen BioTech Co., Ltd.) was used to detect mRNA expression of IL-22 according to the manufacturer's protocol. The reaction system $(20 \mu \mathrm{l})$ was composed of $10 \mu \mathrm{l}$ SYBR Premix EXTaq, $0.5 \mu \mathrm{l}$ forward primer, $0.5 \mu 1$ reverse primer, $2 \mu 1 \mathrm{cDNA}$ and $7 \mu \mathrm{ldd} \mathrm{d}_{2} \mathrm{O}$. The following primer sequences were used: IL-22 forward, 5'-CTCTGCAGCACACTACCCTC-3' and reverse, 5'-CGTTTGGGGCATAGGACAGT-3' and GAPDH forward, 5'-CAATGACCCCTTCATTGACC-3' and reverse, 5'-GAC AAGCTTCCCGTTCTCAG-3'. The thermocycling conditions used were as follows: Initial denaturation at $95^{\circ} \mathrm{C}$ for $10 \mathrm{~min}$; 40 cycles of denaturation at $95^{\circ} \mathrm{C}$ for $1 \mathrm{~min}$, annealing at $60^{\circ} \mathrm{C}$ for $30 \mathrm{sec}$ and elongation at $72^{\circ} \mathrm{C}$ for $30 \mathrm{sec}$. qPCR was performed on an iQ5 system (Bio-Rad Laboratories, Inc.). The $2^{-\Delta \Delta \mathrm{Cq}}$ method (24) was used to calculate the relative expression of IL-22 mRNA against GAPDH. Each sample was tested in triplicate.

CCK- 8 assay. To examine proliferation, MRC-5 cells were seeded at a density of $2 \times 10^{3}$ cells/well in $96-$ well plates. At $0,24,48$ and $72 \mathrm{~h}$ following incubation at $37^{\circ} \mathrm{C}$ and $5 \% \mathrm{CO}_{2}$, $20 \mu$ l CCK-8 reagent (Beyotime Institute of Biotechnology) was added to each well. At the end of the incubation period (24, 48 or $72 \mathrm{~h}), 150 \mu \mathrm{l}$ CCK-8 reaction solution was added into each well and the cells were incubated at $37^{\circ} \mathrm{C}$ for $2 \mathrm{~h}$. Subsequently, the absorbance of each well was measured at a wavelength of $490 \mathrm{~nm}$. Each group was tested in three replicate wells to calculate an average value.

Flow cytometry. At $24 \mathrm{~h}$ post-transfection, $1 \times 10^{6}$ MRC-5 cells or $1 \times 10^{6}$ patient-derived mononuclear lymphocytes were washed twice with precooled PBS. Subsequently, the DNA Reagent kit (cat. no. 340242; BD Biosciences) was used to determine the cell cycle distribution of cells, according to the manufacturer's protocol. Briefly, cells were incubated with $200 \mu \mathrm{l}$ liquid $\mathrm{A}$ at room temperature for $10 \mathrm{~min}$, then with $150 \mu \mathrm{l}$ liquid B at room temperature for $10 \mathrm{~min}$ and finally with $120 \mu 1$ liquid $\mathrm{C}$ in the dark at room temperature for $10 \mathrm{~min}$. Subsequently, the cells were analyzed using a flow cytometer and ModFit software (v3.2; Verity Software House, Inc.). Each experiment was repeated three times.

To assess the ratio of IL- $22^{+}$mononuclear lymphocytes, $1 \times 10^{6} / \mathrm{ml}$ mononuclear lymphocytes were incubated with $250 \mu \mathrm{BD}$ Cytofix/Cytoperm permeabilization solution (BD Biosciences) at $4^{\circ} \mathrm{C}$ in the dark for $20 \mathrm{~min}$. The permeabilization was then stopped by addition of $1 \mathrm{ml}$ PBS. Following centrifugation at $25^{\circ} \mathrm{C}$ and $1,200 \mathrm{x}$ g for $10 \mathrm{~min}$, the cells were mixed with intranuclear factor (IL22+) antibody (1:20; cat. no. IC7821P-025; R\&D Systems, Inc.) before incubation at room temperature in the dark for $30 \mathrm{~min}$. Following washing and resuspension in PBS, the cells were examined by flow cytometry, and data were analyzed with FlowJo v10 software (FlowJo LLC).

Western blotting. MRC- 5 cells $\left(1 \times 10^{6}\right)$ were lysed with cold RIPA buffer ( $600 \mu \mathrm{l}$; Beyotime Institute of Biotechnology) for $30 \mathrm{~min}$ on ice. The mixture was then centrifuged at $12,000 \mathrm{x} \mathrm{g}$ at $4^{\circ} \mathrm{C}$ for $10 \mathrm{~min}$. The protein concentration of the supernatant was determined using a bicinchoninic acid protein concentration determination kit [cat. no. RTP7102; Real-Times (Beijing) Biotechnology Co., Ltd.]. The samples were then mixed with $5 \mathrm{X}$ sodium dodecyl sulfate loading buffer before denaturation in a water bath at $100^{\circ} \mathrm{C}$ for $10 \mathrm{~min}$. Subsequently, the samples $(5 \mu \mathrm{g})$ were subjected to $10 \%$ SDS-PAGE gel electrophoresis at $100 \mathrm{~V}$. The resolved proteins were transferred to PVDF membranes on ice $(250 \mathrm{~mA} ; 1 \mathrm{~h})$ and blocked with $5 \%$ skimmed milk at room temperature for $1 \mathrm{~h}$. Subsequently, the membranes were incubated with the following monoclonal primary mouse anti-human antibodies at $4^{\circ} \mathrm{C}$ overnight: IL-22R1 (1:1,000; cat. no. ab5984; Abcam), collagen type I $\alpha 1$ chain (COL1 $\alpha 1 ; 1: 1,000$; cat. no. ab64883; Abcam), collagen type I $\alpha 2$ chain (COL1 $\alpha 2 ; 1: 1,000$; cat. no. ab196619; Abcam) and GAPDH (1:4,000; cat. no. ab8245; Abcam). After washing with PBS and $0.1 \%$ Tween 20 three times for $15 \mathrm{~min}$, the membranes were incubated with goat anti-mouse horseradish peroxidase-conjugated secondary antibody (1:4,000; cat. no. ab205719; Abcam) for $1 \mathrm{~h}$ at room temperature. Subsequently, the membranes were washed with PBS and $0.1 \%$ Tween 20 three times for $15 \mathrm{~min}$. The membranes were then developed using an ECL kit (Abcam). Image Lab software (version 3.0; Bio-Rad Laboratories, Inc.) was used to acquire and analyze imaging signals. The relative contents of target proteins were expressed against GAPDH. Each experiment was repeated three times.

Statistical analysis. Data were analyzed using SPSS software (version 19.0; IBM, Corp.). Data are presented as the mean \pm SD. Data were tested for normality. Data containing multiple groups were analyzed using one-way ANOVA followed by the relevant post hoc test. In cases of homogeneity of variance, Least Significant Difference or Student-Newman-Keuls post hoc tests were used. In cases of heterogeneity of variance, Tamhane's T2 or Dunnett's T3 post hoc tests were used. Comparisons between two groups were performed using unpaired Student's t-test. $\mathrm{P}<0.05$ was considered to indicate a statistically significant difference.

\section{Results}

Expression of IL-22 is elevated in peripheral blood from children with asthma, and this promotes the proliferation of MRC-5 cells possibly via upregulating the levels of COLI 1 and COL1 22 . The IL-22 content of serum derived from children with asthma (asthma serum) and healthy children (healthy serum) was determined by ELISA. The IL-22 content of asthma serum $(104.5 \pm 14.7 \mathrm{ng} / \mu \mathrm{l})$ was significantly higher than that of healthy serum $(23.5 \pm 6.3 \mathrm{ng} / \mu \mathrm{l} ; \mathrm{P}<0.05$; Fig. 1A). Following a 24-h incubation with healthy or asthma serum, the level of IL-22R1 mRNA in MRC-5 cells was determined 
A

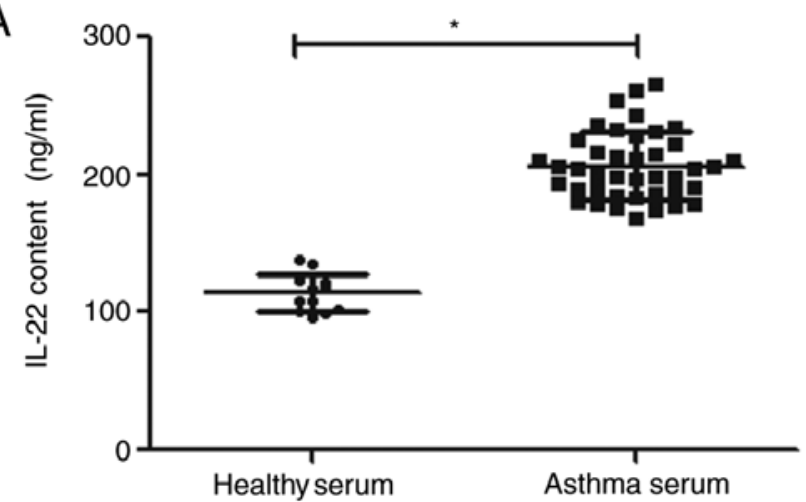

B
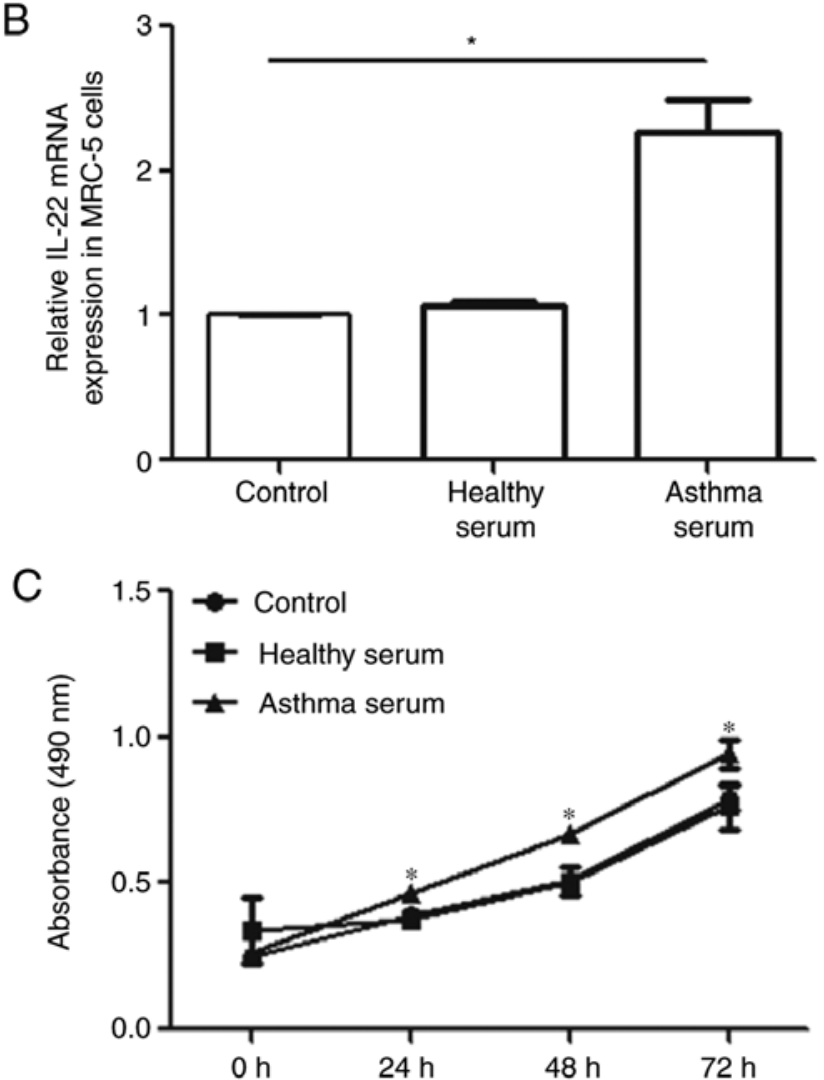
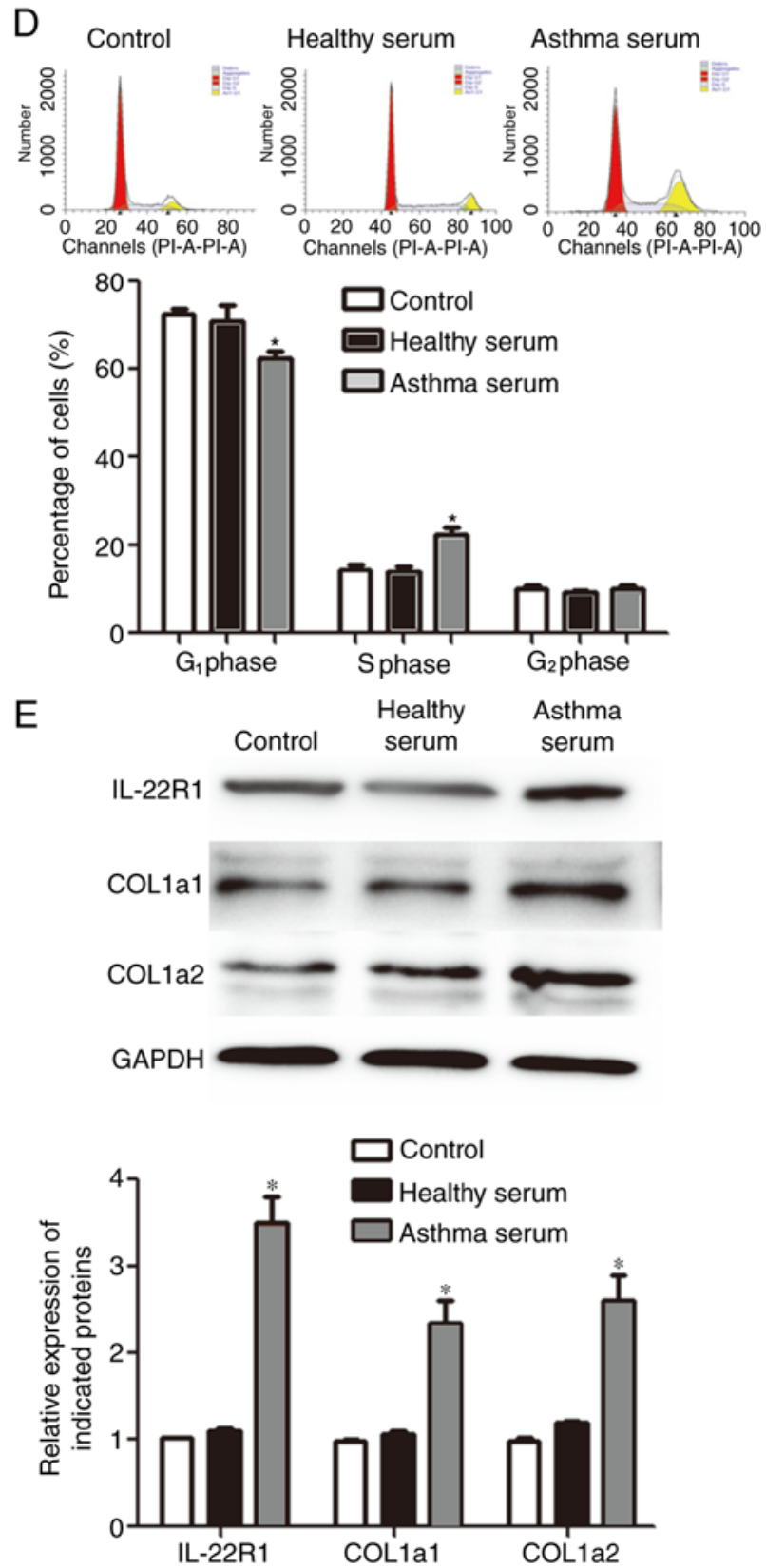

Figure 1. Upregulated IL-22 expression in asthma promotes the proliferation and collagen synthesis of MRC-5 cells. (A) Content of IL-22 in serum from healthy children (healthy serum) and children with asthma (asthma serum), determined by ELISA. "P $<0.05$, as indicated. (B) Expression of IL-22 mRNA in untreated MRC-5 cells and MRC-5 cells treated for $24 \mathrm{~h}$ with healthy or asthma serum. Reverse transcription-quantitative PCR was performed to determine IL-22 mRNA expression. "P<0.05, as indicated. (C) Proliferation of MRC-5 cells incubated with healthy or asthma serum. The Cell Counting Kit- 8 assay was peformed to study cell proliferation. " $\mathrm{P}<0.05$ vs. control. (D) Cell cycle distribution analysis of MRC-5 cells incubated with healthy or asthma serum. Flow cytometry was performed to assess the cell cycle distribution of MRC-5 cells. "P<0.05 vs. control of the same cell cycle phase. (E) Expression of IL-22R1, COL1 $\alpha 1$ and COL1 $\alpha 2$ proteins in MRC-5 cells incubated with healthy or asthma serum. Western blotting was performed to determine the levels of protein expression. " $\mathrm{P}<0.05$ vs. control of the same protein. IL, interleukin; IL-22R1, IL-22 receptor 1; COL1 $\alpha 1$, collagen type I $\alpha 1$ chain; COL1 $\alpha 2$, collagen type I $\alpha 2$ chain.

by RT-qPCR. IL-22R1 mRNA expression in MRC-5 cells treated with asthma serum was significantly higher than that of untreated MRC-5 cells ( $\mathrm{P}<0.05$; Fig. 1B), and the expression in the control group was not statistically significant compared with the healthy serum group (Fig. 1B). The proliferation of MRC-5 cells treated with asthma serum was significantly higher than that of untreated MRC-5 cells at 24, 48 and $72 \mathrm{~h}$ post-treatment $(\mathrm{P}<0.05$; Fig. $1 \mathrm{C})$, and proliferation in the control group was not statistically significant compared with the healthy serum group (Fig. 1C). The proportion of cells in the $\mathrm{G}_{1}$ phase was significantly lower in MRC-5 cells treated with asthma serum than in the control $(\mathrm{P}<0.05$; Fig. 1D), and the proportion of $G_{1}$ cells in the control group was not statistically significant compared with the healthy serum group (Fig. 1D). However, the proportion of cells in the $\mathrm{S}$ phase was higher in MRC-5 cells treated with asthma serum than that in the control $(\mathrm{P}<0.05$; Fig. 1D), and that in control group was not different from that in healthy serum group (P>0.05; Fig. 1D). Furthermore, the protein expression levels of IL-22R1, COL1 $\alpha 1$ and COL $1 \alpha 2$ in MRC-5 cells 
treated with asthma serum were significantly higher than in the control $(\mathrm{P}<0.05$; Fig. 1E), and protein expression in the control group was not statistically significant compared with the healthy serum group (Fig. 1E). To further investigate the involvement of IL-22 in regulating the biological functions of MRC-5 cells, rescue experiments using an IL-22 antibody were performed. After the addition of IL-22 antibody, the proliferation of MRC-5 cells treated with asthma serum was reduced compared with the asthma serum-only group, to a level similar to the control group (Fig. 2A). Moreover, the transition of cells from the $G_{1}$ to $S$ phase of the cell cycle was inhibited in the IL-22 antibody group compared with the asthma serum-only group, to levels similar to the control group (Fig. 2B). IL-22R1 protein expression in the IL-22 antibody group was significantly higher than that in the control group $(\mathrm{P}<0.05$; Fig. $2 \mathrm{C})$ and was similar to that of the asthma serum-only group. Furthermore, COL1 $\alpha 1$ and COL1 $\alpha 2$ protein expression in the IL-22 antibody group was significantly lower than that of the asthma serum-only group $(\mathrm{P}<0.05$; Fig. 2C). Collectively, these results suggested that IL-22 expression was elevated in the peripheral blood of children with asthma, and that the increased proliferative ability of MRC-5 cells may occur via upregulation of COL1 $1 \alpha 1$ and COL1 $\alpha 2$ expression.

$I L-22$ exerts its biological functions via IL-22RI. The transfection efficiency of siR-IL22R1 and IL-22R1 is presented in Fig. S1. To test whether IL-22 transmits intracellular signals via IL-22R1, IL-22R1 was knocked down or overexpressed in MRC-5 cells and the cells were subsequently stimulated with IL-22. The expression of IL-22R1, COL1 $\alpha 1$ and COL1 $\alpha 2$ in the siR-IL-22R1 group was significantly lower than that in the siR-NC group $(\mathrm{P}<0.05)$. Furthermore, the expression of IL-22R1, COL1 $\alpha 1$ and COL1 $\alpha 2$ in the IL-22R1 overexpression group was significantly higher than that in the $\mathrm{NC}$ group $(\mathrm{P}<0.05 ;$ Fig. 3A). These results indicated that the transfection experiments were successful. IL-22-induced proliferation was inhibited in the siR-IL-22R1 group, but was increased in the IL-22R1 overexpression group compared with the siR-NC and $\mathrm{NC}$ groups, respectively $(\mathrm{P}<0.05$; Fig. $3 \mathrm{~B})$. The proportion of cells in the $\mathrm{S}$ phase in the siR-IL-22R1 group was reduced, while that in the IL-22R1 overexpression group was increased compared with the siR-NC and $\mathrm{NC}$ groups, respectively $(\mathrm{P}<0.05$; Fig. $3 \mathrm{C})$. The results indicated that IL-22 exerted its biological functions via IL-22R1.

$I L-22 / I L-22 R 1$ regulates the proliferation and expression of COL1al and COL1a2 in MRC-5 cells via the JAK/STAT3 signaling pathway. To further study the mechanism by which IL-22/IL-22R1 regulated the biological functions of fibroblasts, the present study investigated the effect of the JAK/STAT3 signaling pathway inhibitor stattic $(2 \mu \mathrm{M})$ on MRC- 5 cells. The addition of stattic reduced IL-22-induced proliferation of MRC-5 cells in the IL-22R1 overexpression group $(\mathrm{P}<0.05$; Fig. 4A). Furthermore, the addition of stattic limited the effect of IL-22 on the expression of COL1 $\alpha 1$ and COL1 $\alpha 2$ ( $\mathrm{P}<0.05$; Fig. 4B). Additionally, flow cytometry analysis suggested that the addition of static decreased the effect of IL-22 on the proportion of cells transitioning from the $\mathrm{G}_{1}$ to the $\mathrm{S}$ phase $(\mathrm{P}<0.05$; Fig. $4 \mathrm{C})$. Overall, these results
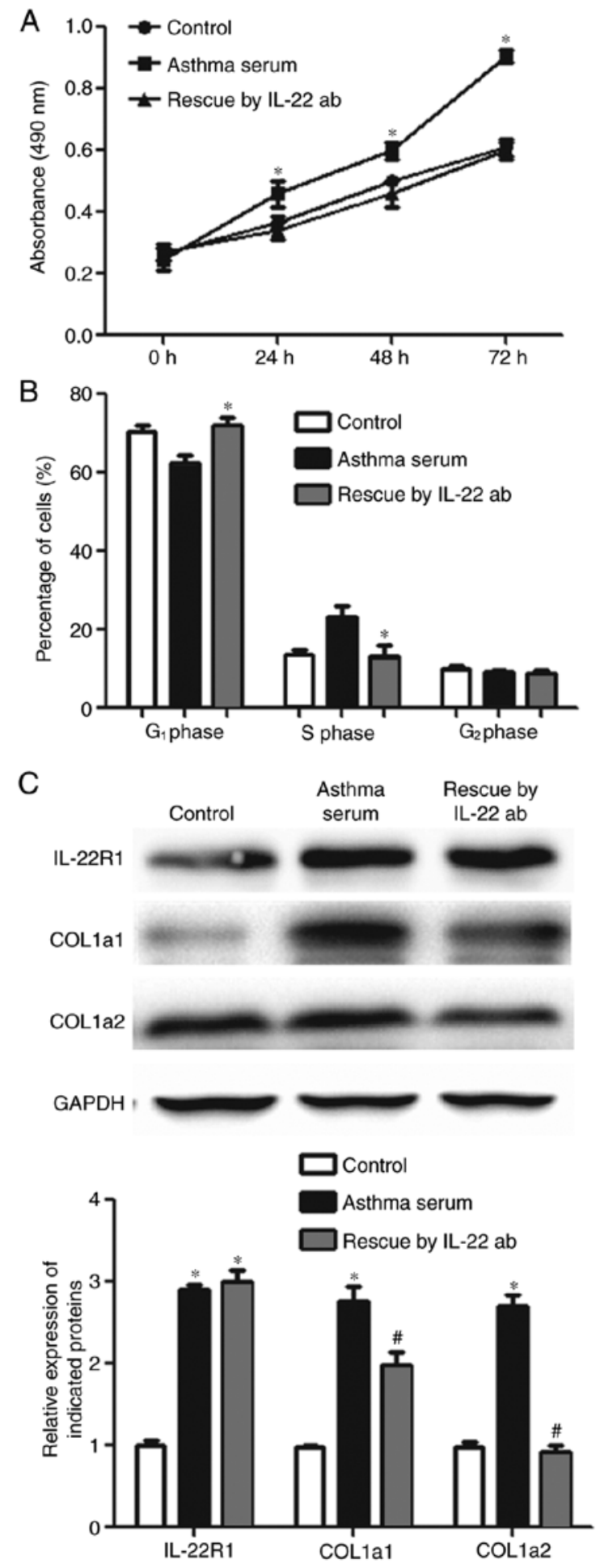

Figure 2. IL-22 antibody rescued the regulatory effect of serum derived from children with asthma on the biological functions of MRC-5 cells. Cells in the control group were not treated with serum or IL-22 antibody. (A) Proliferation of MRC-5 cells incubated with serum from children with asthma (asthma serum), in the presence or absence of IL-22 antibody. The Cell Counting Kit- 8 assay was performed to study cell proliferation. ${ }^{*} \mathrm{P}<0.05$ vs. control. (B) Cell cycle distribution analysis of MRC-5 cells incubated with asthma serum, in the presence or absence of IL-22 antibody. Flow cytometry was performed to assess the cell cycle distribution of MRC -5 cells. ${ }^{*} \mathrm{P}<0.05$ vs asthma serum group of the same cell cycle phase. (C) Expression of IL-22R1, COL $1 \alpha 1$ and COL1 $\alpha 2$ proteins in MRC-5 cells incubated with asthma serum, in the presence or absence of IL-22 antibody. Western blotting was performed to determine the levels of protein expression. ${ }^{*} \mathrm{P}<0.05 \mathrm{vs}$. control of the same protein; ${ }^{\text {}} \mathrm{P}<0.05 \mathrm{vs}$. asthma serum group of the same protein. IL, interleukin; ab, antibody; IL-22R1, IL-22 receptor 1; COL1 $\alpha 1$, collagen type I $\alpha 1$ chain; COL1 $\alpha 2$, collagen type I $\alpha 2$ chain. 

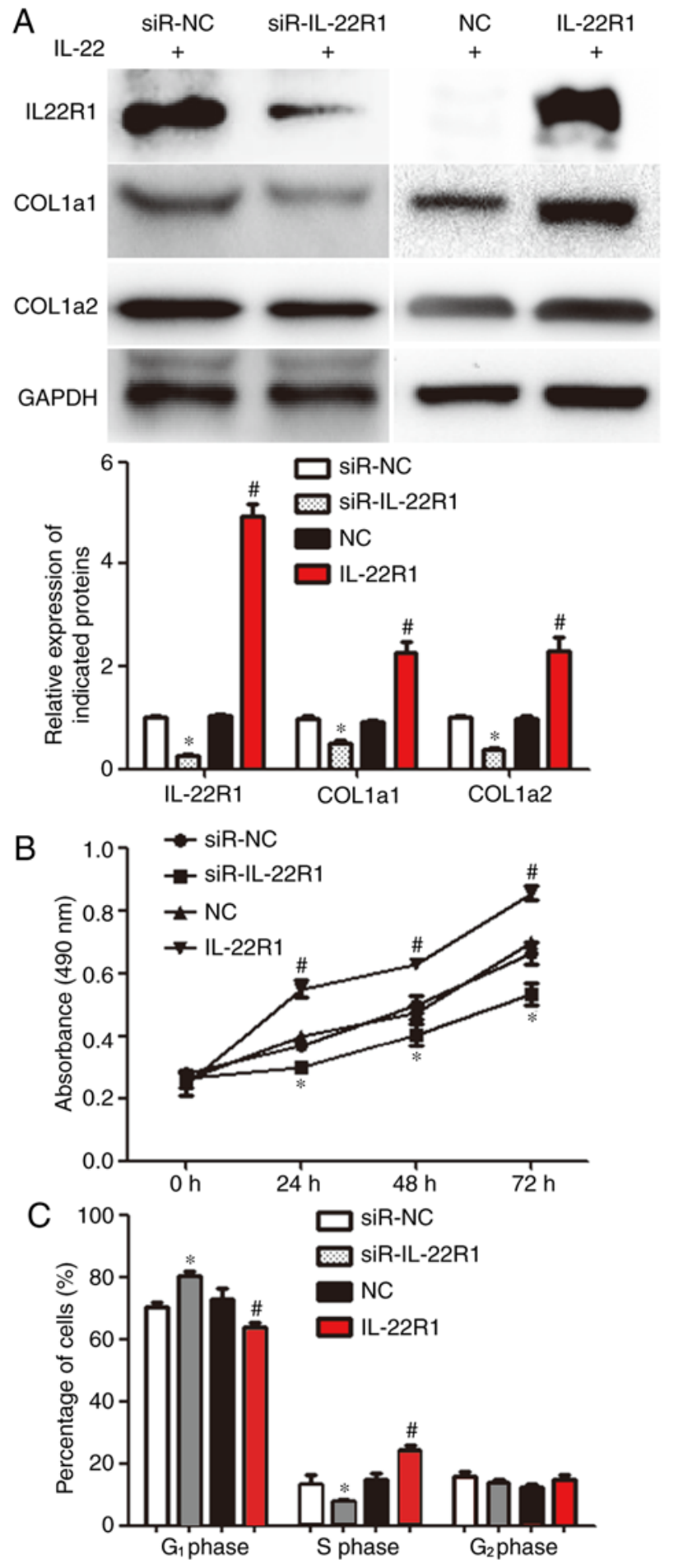

Figure 3. Effect of IL-22R1 knockdown or overexpression on the proliferation and collagen synthesis of MRC-5 cells. (A) Expression of IL-22R1, COL1 $\alpha 1$ and COL1 $\alpha 2$ proteins in MRC-5 cells transfected with siR-IL-22R1, siR-NC, an IL-22R1 overexpression plasmid or an NC plasmid, incubated with serum from children with asthma (asthma serum). Western blotting was performed to determine the levels of protein expression. ${ }^{*} \mathrm{P}<0.05$ vs. siR-NC; ${ }^{\text {P }}<0.05$ vs. NC. (B) Proliferation of MRC- 5 cells transfected with siR-IL-22R1, siR-NC, an IL-22R1 overexpression plasmid or an NC plasmid, incubated with asthma serum. The Cell Counting Kit- 8 assay was performed to study cell proliferation. ${ }^{*} \mathrm{P}<0.05$ vs. siR-NC; ${ }^{\#} \mathrm{P}<0.05$ vs. NC. (C) Cell cycle distribution analysis of MRC-5 cells transfected with siR-IL-22R1, siR-NC, an IL-22R1 overexpression plasmid or an NC plasmid, incubated with asthma serum. Flow cytometry was performed to assess the cell cycle distribution of MRC- 5 cells. ${ }^{~} \mathrm{P}<0.05$ vs. siR-NC of the same cell cycle phase; ${ }^{*} \mathrm{P}<0.05$ vs. $\mathrm{NC}$ of the same cell cycle phase. IL, interleukin; IL-22R1, IL-22 receptor 1; COL $1 \alpha 1$, collagen type I $\alpha 1$ chain; COL $1 \alpha 2$, collagen type I $\alpha 2$ chain; siR, small-interfering RNA; NC, negative control.
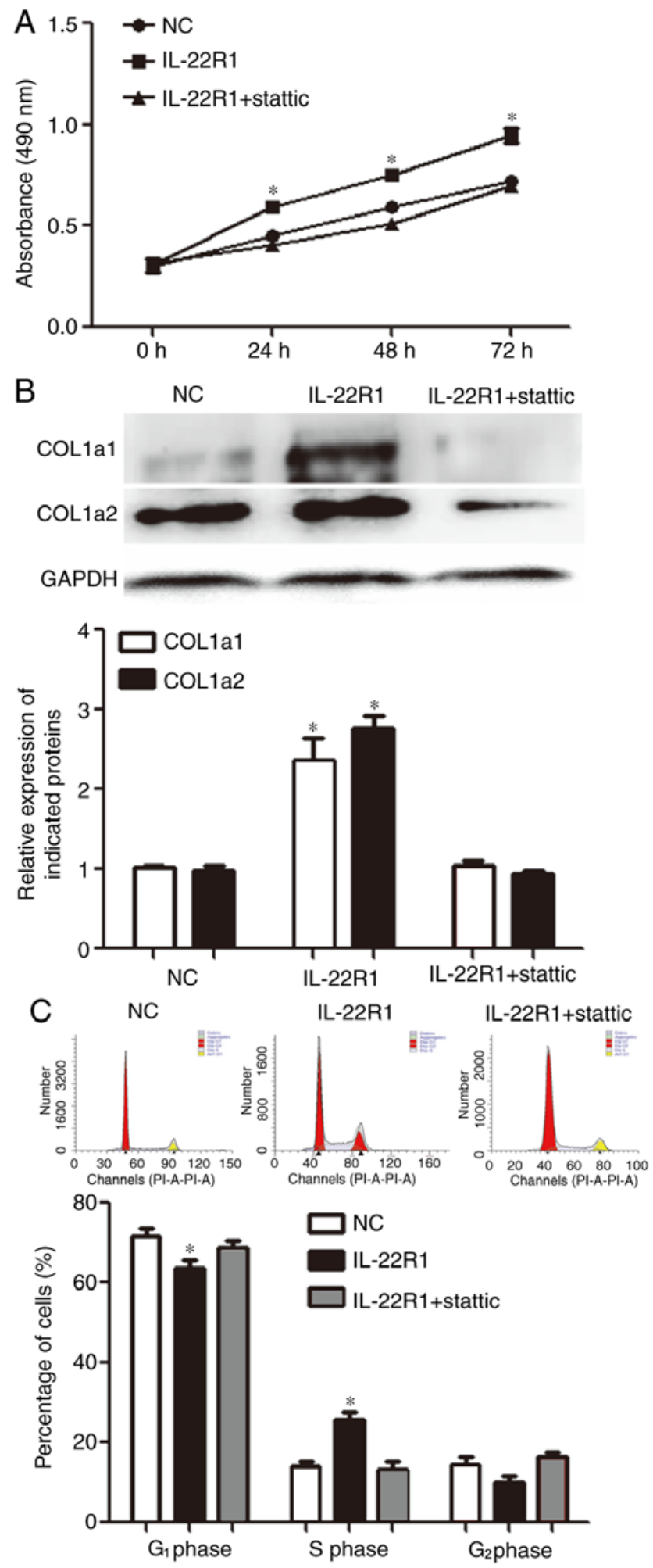

Figure 4. IL-22/IL-22R1 interaction regulates the biological functions of MRC-5 cells via the JAK/STAT3 signaling pathway. Cells in the NC group were untreated. (A) Proliferation of MRC-5 cells overexpressing IL-22R1, in the presence or absence of the JAK/STAT3 signaling pathway inhibitor stattic $(2 \mu \mathrm{M})$. The Cell Counting Kit- 8 assay was performed to study cell proliferation. " $\mathrm{P}<0.05$ vs. NC. (B) Expression of COL $1 \alpha 1$ and COL1 12 proteins in MRC- 5 cells overexpressing IL-22R1 in the presence or absence of stattic $(2 \mu \mathrm{M})$. Western blotting was performed to determine the levels of protein expression. " $\mathrm{P}<0.05$ vs. NC of the same protein. (C) Cell cycle distribution analysis of MRC-5 cells overexpressing IL-22R1 in the presence or absence of stattic $(2 \mu \mathrm{M})$. Flow cytometry was performed to assess the cell cycle distribution of MRC- 5 cells. " $\mathrm{P}<0.05$ vs. $\mathrm{NC}$ of the same cell cycle phase. IL, interleukin; IL-22R1, IL-22 receptor 1; NC, negative control; COL1 $\alpha 1$, collagen type I $\alpha 1$ chain; COL $1 \alpha 2$, collagen type I $\alpha 2$ chain. 
A
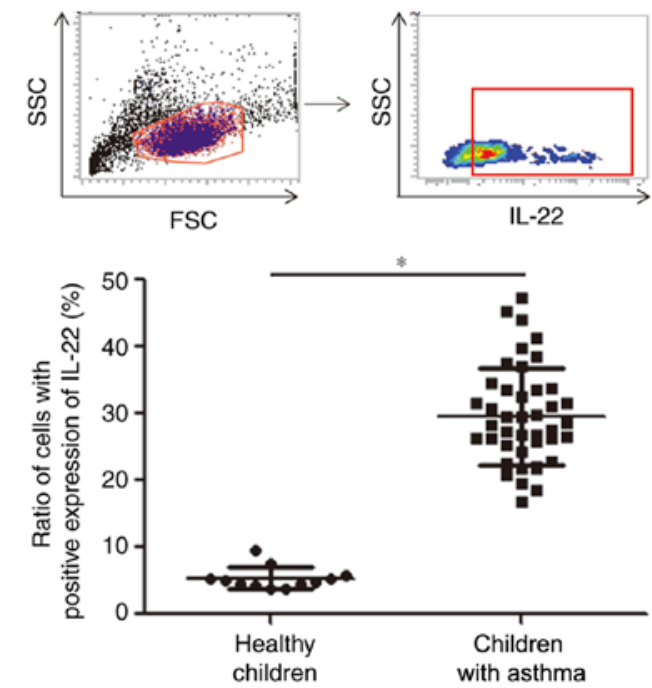

C

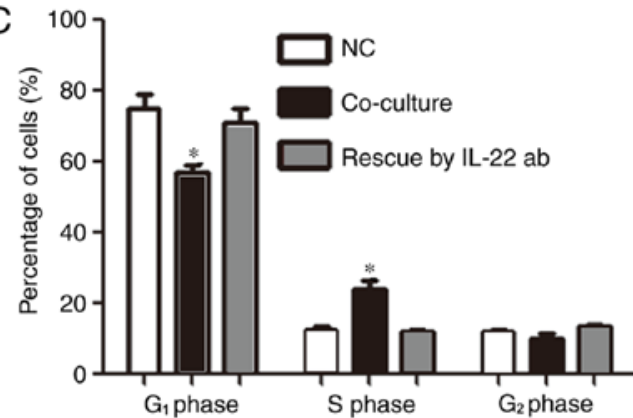

B

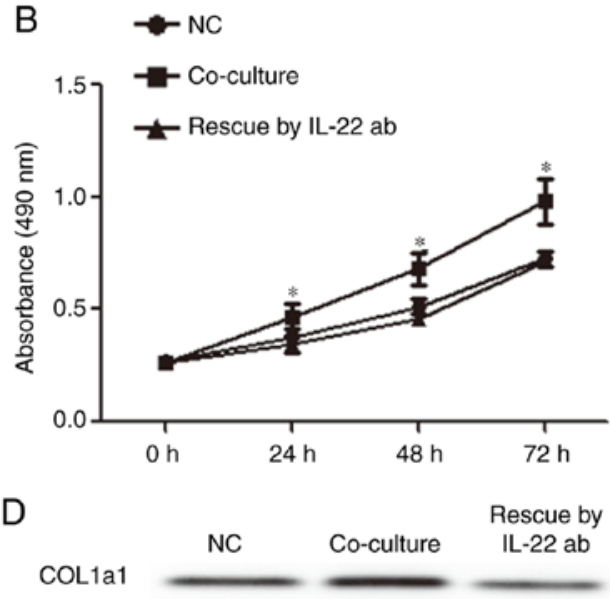

COL1a2

GAPDH

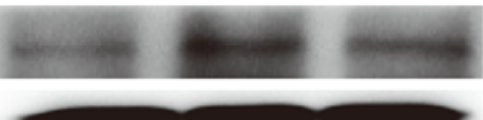

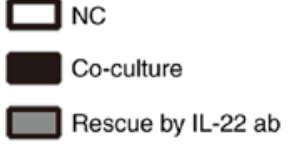

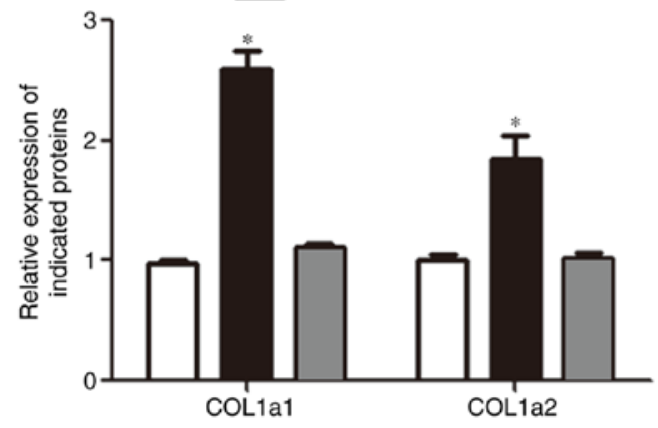

Figure 5. Effect of IL-22+ mononuclear lymphocytes on the biological functions of MRC-5 cells. Cells in the NC group were untreated. (A) Ratio of IL-22+ mononuclear lymphocytes in peripheral blood from healthy children and children with asthma, as determined by flow cytometry. "P $<0.05$ vs. healthy children. (B) Proliferation of MRC-5 cells co-cultured with mononuclear lymphocytes derived from children with asthma, in the presence or absence of IL-22 antibody. The Cell Counting Kit- 8 assay was performed to study cell proliferation. "P $<0.05$ vs. NC. (C) Cell cycle distribution analysis of MRC- 5 cells co-cultured with mononuclear lymphocytes derived from children with asthma, in the presence or absence of IL-22 antibody. Flow cytometry was performed to assess the cell cycle distribution of MRC-5 cells. "P $\mathrm{P}<0.05$ vs. NC group of the same cell cycle phase. (D) Expression of COL1 $\alpha 1$ and COL1 $\alpha 2$ proteins in MRC-5 cells co-cultured with mononuclear lymphocytes derived from children with asthma, in the presence or absence of IL-22 antibody. Western blotting was performed to determine the levels of protein expression. "P<0.05 vs. NC of the same protein. IL, interleukin; NC, negative control; COL1 $\alpha 1$, collagen type I $\alpha 1$ chain; COL1 $\alpha 2$, collagen type I $\alpha 2$ chain; SSC, side scatter; FSC forward scatter.

suggested that IL-22 regulated the proliferation and expression of COL $1 \alpha 1$ and COL $1 \alpha 2$ proteins in MRC-5 cells, potentially via the JAK/STAT3 signaling pathway.

Mononuclear lymphocytes from children with asthma stimulate the proliferation and secretory function of fibroblasts via secretion of $I L-22$. To analyze the origin of IL-22, mononuclear lymphocytes isolated from the peripheral blood of healthy children and children with asthma were assessed by flow cytometry. The ratio of $\mathrm{IL}^{-22^{+}}$mononuclear lymphocytes in the asthma group was significantly higher than that in the healthy group $(\mathrm{P}<0.05$; Fig. 5A). Then, mononuclear lymphocytes from children with asthma were co-cultured with MRC-5 cells. MRC-5 cell proliferation was significantly higher in the co-cultured group than in the NC group $(\mathrm{P}<0.05$; Fig. 5B). Alternatively, incubation of co-cultured
MRC-5 cells with IL-22 antibody reduced proliferation to a level similar to that of the NC group ( $P>0.05$; Fig. 5B). Furthermore, the proportion of cells transitioning from $G_{1}$ to $\mathrm{S}$ phase was higher in the co-cultured group than in the $\mathrm{NC}$ group $(\mathrm{P}<0.05$; Fig. 5C), while incubation of the co-cultured cells with IL-22 antibody significantly reduced the proportion of cells transitioning from $\mathrm{G}_{1}$ to $\mathrm{S}$ phase compared with the co-culture group $(\mathrm{P}<0.05$; Fig. $5 \mathrm{C})$. The expression of COL $1 \alpha 1$ and COL $1 \alpha 2$ in the co-cultured group was higher than that in the NC group $(\mathrm{P}<0.05$; Fig. 5D), and incubation of the co-cultured cells with IL-22 antibody reduced COL1 $\alpha 1$ and COL1 $\alpha 2$ protein expression to levels similar to the NC group ( $\mathrm{P}>0.05$; Fig. 5D). These results indicated that mononuclear lymphocytes derived from children with asthma stimulated the proliferation and secretory function of fibroblasts via secretion of IL-22. 


\section{Discussion}

Subepithelial lung fibroblast proliferation, transformation to myofibroblasts and synthesis of extracellular matrix are the main mechanisms leading to subepithelial fibrosis in patients with asthma $(25,26)$. IL-22 is an immune-related cytokine that was discovered in previous years and plays a role in the occurrence and development of psoriasis, arthritis and cancer $(22,27,28)$. Previously, it was reported that IL-22 promotes allergic airway inflammation in sensitized mice in vivo (17). In addition, IL-22 promotes the occurrence and development of KRAS-mutant lung cancer by inducing pre-cancerous immune responses and preserving stem cell characteristics (29). These studies suggest that IL-22 has a role in pulmonary inflammation and tumor formation. In the present study, the expression of IL-22 in the peripheral serum of children with asthma was significantly increased, compared with healthy children. In vitro co-culture experiments suggested that asthma serum could promote the proliferation of MRC-5 cells. After co-culture with asthma serum, the expression of COL $1 \alpha 1$ and COL $1 \alpha 2$, the main components of type I collagen, was upregulated. In addition, asthma serum enhanced the expression of IL-22R1 in MRC-5 cells after co-culture, suggesting that IL-22 regulated MRC-5 cells by binding to IL-22R1. Interestingly, the addition of IL-22 antibody reduced the proliferation of MRC-5 cells and their ability to synthesize collagen. IL-22R1 knockdown and overexpression in MRC-5 cells suggested that the effects of IL-22 stimulation were decreased or increased, respectively, suggesting that IL-22 regulated the proliferation of MRC-5 cells and their ability to synthesize collagen via IL-22R1.

The IL-22/IL-22R1 signaling pathway has been reported to play a role in immunoregulation and tumorigenesis $(30,31)$. Furthermore, it has been reported that the IL-22/IL-22R1 signaling pathway can transmit extracellular signals via the JAK/STAT3 signaling pathway, thus regulating various biological processes $(32,33)$. For example, IL-22 promotes stem cell characteristics and tumorigenesis of pancreatic cancer via the JAK/STAT3 signaling pathway (32). Additionally, upregulation of IL-10R2 can activate the IL-22/STAT3 signaling pathway and promote the occurrence and development of colon cancer (33). In the present study, it was suggested that the IL-22/IL-22R1 signaling pathway activated the JAK/STAT3 signaling pathway. The application of a STAT3 inhibitor blocked the effects of the IL-22/IL-22R1 signaling pathway on MRC-5 proliferation and collagen synthesis. These results suggested that IL-22/IL-22R1 may promote fibroblast proliferation and collagen synthesis via the JAK/STAT3 signaling pathway during pulmonary fibrosis. Previous studies have shown that IL-22 is secreted by various immune cells such as type $1 \mathrm{~T}$ helper cells, as well as certain cancer cells such as pancreatic cancer and bladder cancer cells, including mononuclear lymphocytes $(29,34)$. The present study suggested that the expression of IL-22 in peripheral mononuclear lymphocytes of children with asthma was significantly upregulated compared with healthy children. Therefore, mononuclear lymphocytes may activate the IL-22/IL-22R1 and JAK/STAT3 signaling pathways when migrating into the lungs. The mechanism of this process is not completely understood and requires further investigation.
In conclusion, the present study suggested that the synthesis and secretion of IL-22 by peripheral blood mononuclear lymphocytes in children with asthma was enhanced. In addition, the IL-22/IL-22R1 signaling pathway promoted MRC-5 cell proliferation and collagen synthesis, potentially via the JAK/STAT3 signaling pathway and thus, may regulate airway subepithelial fibrosis. The present study only focused on the function of IL-22, but several other cytokines are present in peripheral serum and were not analyzed. Therefore, further investigation of the expression profiles of various other cytokines in peripheral serum is required.

\section{Acknowledgements}

The authors would like to thank Dr Li Jiang of Nanchong Central Hospital, The Second Clinical Medical College, North Sichuan Medical College for her valuable suggestions.

\section{Funding}

No funding was received.

\section{Availability of data and materials}

The datasets used and/or analyzed during the present study are available from the corresponding author on reasonable request.

\section{Authors' contributions}

JL designed the study. JL, BS and JB performed the experiments. JL and BS analyzed the data. All authors collaborated to interpret the results and write the manuscript. All authors read and approved the final manuscript.

\section{Ethical approval and consent to participate}

All procedures performed in the present study were approved by the Ethics Committee of North Sichuan Medical College (approval no. NS-CE-017-03). Written informed consent was obtained from all patients or their families.

\section{Patient consent for publication}

Not applicable.

\section{Competing interests}

The authors declare that they have no competing interests.

\section{References}

1. Reese SE, Xu CJ, den Dekker HT, Lee MK, Sikdar S, RuizArenas C, Merid SK, Rezwan FI, Page CM, Ullemar V, et al: Epigenome-wide meta-analysis of DNA methylation and childhood asthma. J Allergy Clin Immunol 143: 2062-2074, 2019.

2. Saglani S and Custovic A: Childhood asthma: Advances using machine learning and mechanistic studies. Am J Respir Crit Care Med 199: 414-422, 2019.

3. Eldeirawi K, Kunzweiler C, Zenk S, Finn P, Nyenhuis S, Rosenberg $\mathrm{N}$ and Persky V: Associations of urban greenness with asthma and respiratory symptoms in Mexican American children. Ann Allergy Asthma Immunol 122: 289-295, 2019. 
4. Kim YM, Kim J, Cheong HK, Jeon BH and Ahn K: Exposure to phthalates aggravates pulmonary function and airway inflammation in asthmatic children. PLoS One 13: e0208553, 2018.

5. Biagini Myers JM, Schauberger E, He H, Martin LJ, Kroner J, Hill GM, Ryan PH, LeMasters GK, Bernstein DI, Lockey JE, et al: A pediatric asthma risk score to better predict asthma development in young children. J Allergy Clin Immunol 143: 1803-1810.e2, 2019.

6. Lezmi G and de Blic J: Assessment of airway inflammation and remodeling in children with severe asthma: The next challenge. Pediatr Pulmonol 53: 1171-1173, 2018.

7. Fehrenbach $\mathrm{H}$, Wagner $\mathrm{C}$ and Wegmann $\mathrm{M}$ : Airway remodeling in asthma: What really matters. Cell Tissue Res 367: 551-569, 2017.

8. Kumari A, Singh DK, Dash D and Singh R: Intranasal curcumin protects against LPS-induced airway remodeling by modulating toll-like receptor-4 (TLR-4) and matrixmetalloproteinase-9 (MMP-9) expression via affecting MAP kinases in mouse model. Inflammopharmacology 27: 731-748, 2019.

9. Lin SC, Chou HC, Chen CM and Chiang BL: Anti-thymic stromal lymphopoietin antibody suppresses airway remodeling in asthma through reduction of MMP and CTGF. Pediatr Res 86 : 181-187, 2019.

10. Zhou J, Bai W, Liu Q, Cui J and Zhang W: Silencing of ADAM33 restrains proliferation and induces apoptosis of airway smooth muscle cells in ovalbumin-induced asthma model. J Cell Biochem, Nov 18, 2018 (Epub ahead of print).

11. Cao L, Liu F, Liu Y, Liu T, Wu J, Zhao J, Wang J, Li S, Xu J and Dong L: TSLP promotes asthmatic airway remodeling via p38-STAT3 signaling pathway in human lung fibroblast. Exp Lung Res 44: 288-301, 2018.

12. Yadav SK, Shah SD and Penn RB: Give me a fork: Can autophagy research solve the riddle of airway remodeling in asthma? Am J Respir Cell Mol Biol 60: 494-496, 2019.

13. Kaczmarek KA, Clifford RL and Knox AJ: Epigenetic changes in airway smooth muscle as a driver of airway inflammation and remodeling in asthma. Chest 155: 816-824, 2019.

14. Rodrigues APD, Bortolozzo ASS, Arantes-Costa FM, Saraiva-Romanholo BM, de Souza FCR, Brüggemann TR, Santana FPR, de Brito MV, Bonturi CR, Nunes NNDS, et al: A plant proteinase inhibitor from enterolobium contortisiliquum attenuates airway hyperresponsiveness, inflammation and remodeling in a mouse model of asthma. Histol Histopathol 34: 537-552, 2019.

15. McAlinden KD, Deshpande DA, Ghavami S, Xenaki D, Sohal SS, Oliver BG, Haghi M and Sharma P: Autophagy activation in asthma airways remodeling. Am J Respir Cell Mol Biol 60: 541-553, 2019.

16. Brunner PM, Pavel AB, Khattri S, Leonard A, Malik K, Rose S, Jim On S, Vekaria AS, Traidl-Hoffmann C, Singer GK, et al: Baseline IL-22 expression in patients with atopic dermatitis stratifies tissue responses to fezakinumab. J Allergy Clin Immunol 143: 142-154, 2019.

17. Leyva-Castillo JM, Yoon J and Geha RS: IL-22 promotes allergic airway inflammation in epicutaneously sensitized mice. J Allergy Clin Immunol 143: 619-630.e7, 2019.

18. Geng H, Bu HF, Liu F, Wu L, Pfeifer K, Chou PM, Wang X, Sun J, Lu L, Pandey A, et al: In inflamed intestinal tissues and epithelial cells, interleukin 22 signaling increases expression of H19 long noncoding RNA, which promotes mucosal regeneration. Gastroenterology 155: 144-155, 2018.

19. Chen E, Cen Y, Lu D, Luo W and Jiang H: IL-22 inactivates hepatic stellate cells via downregulation of the TGF- $\beta 1 /$ Notch signaling pathway. Mol Med Rep 17: 5449-5453, 2018.
20. Almolda B, Costa M, Montoya M, González B and Castellano B: Increase in Th17 and T-reg lymphocytes and decrease of IL22 correlate with the recovery phase of acute EAE in rat. PLoS One 6: e27473, 2011.

21. Pollock RA, Zaman L, Chandran V and Gladman DD: Epigenome-wide analysis of sperm cells identifies IL22 as a possible germ line risk locus for psoriatic arthritis. PLoS One 14: $\mathrm{e} 0212043,2019$.

22. He Y, Yang Y, Xu J, Liao Y, Liu L, Deng L and Xiong X: IL22 drives cutaneous melanoma cell proliferation, migration and invasion through activation of miR-181/STAT3/AKT axis. J Cancer 11: 2679-2687, 2020.

23. Bao Y: Guidelines for the diagnosis and treatment of bronchial asthma in children (2016 edition). Data Collection of the 20th National Pediatric Academic Conference on Integration of Traditional Chinese and Western Medicine: 57-71, 2016.

24. Livak KJ and Schmittgen TD: Analysis of relative gene expression data using real-time quantitative PCR and the 2(-Delta Delta C(T)) method. Methods 25: 402-408, 2001.

25. Campa CC, Silva RL, Margaria JP, Pirali T, Mattos MS, Kraemer LR, Reis DC, Grosa G, Copperi F, Dalmarco EM, et al: Inhalation of the prodrug PI3K inhibitor CL27c improves lung function in asthma and fibrosis. Nat Commun 9: 5232, 2018.

26. Sun Q, Fang L, Tang X, Lu S, Tamm M, Stolz D and Roth M: TGF- $\beta$ upregulated mitochondria mass through the $\mathrm{SMAD} 2 / 3 \rightarrow \mathrm{C} / \mathrm{EBP} \beta \rightarrow \mathrm{PRMT} 1$ signal pathway in primary human lung fibroblasts. J Immunol 202: 37-47, 2019.

27. Reeder KM, Mackel JJ, Godwin MS, Dunaway CW, Blackburn JP, Patel RP and Steele C: Role of common $\gamma$-Chain cytokines in lung interleukin-22 regulation after acute exposure to aspergillus fumigatus. Infect Immun 86: e00157-18, 2018.

28. Trevejo-Nunez G, Elsegeiny W, Conboy P, Chen K and Kolls JK: Critical role of IL-22/IL22-RA1 signaling in pneumococcal pneumonia. J Immunol 197: 1877-1883, 2016.

29. Khosravi N, Caetano MS, Cumpian AM, Unver N, De la Garza Ramos C, Noble O, Daliri S, Hernandez BJ, Gutierrez BA, Evans SE, et al: IL22 promotes kras-mutant lung cancer by induction of a protumor immune response and protection of stemness properties. Cancer Immunol Res 6: 788-797, 2018.

30. Rompré-Brodeur A, Shinde-Jadhav S, Ayoub M, Piccirillo CA, Seuntjens J, Brimo F, Mansure JJ and Kassouf W: PD-1/PD-L1 immune checkpoint inhibition with radiation in bladder cancer: In situ and abscopal effects. Mol Cancer Ther 19: 211-220, 2020.

31. Zhou Y, Hou W, Xu K, Han D, Jiang C, Mou K, Li Y, Meng L and Lu S: The elevated expression of Th17-related cytokines and receptors is associated with skin lesion severity in early systemic sclerosis. Hum Immunol 76: 22-29, 2015.

32. He W, Wu J, Shi J, Huo YM, Dai W, Geng J, Lu P, Yang MW, Fang Y, Wang W, et al: IL22RA1/STAT3 signaling promotes stemness and tumorigenicity in pancreatic cancer. Cancer Res 78: 3293-3305, 2018.

33. Khare V, Paul G, Movadat O, Frick A, Jambrich M, Krnjic A, Marian B, Wrba F and Gasche C: IL10R2 overexpression promotes IL22/STAT3 signaling in colorectal carcinogenesis. Cancer Immunol Res 3: 1227-1235, 2015.

34. Eggenhofer E, Sabet-Rashedi M, Lantow M, Renner P, Rovira J, Koehl GE, Schlitt HJ, Geissler EK and Kroemer A: ROR $\gamma \mathrm{t}(+)$ IL-22-producing NKp46(+) cells protect from hepatic ischemia reperfusion injury in mice. J Hepatol 64: 128-134, 2016.

This work is licensed under a Creative Commons Attribution-NonCommercial-NoDerivatives 4.0 International (CC BY-NC-ND 4.0) License. 